
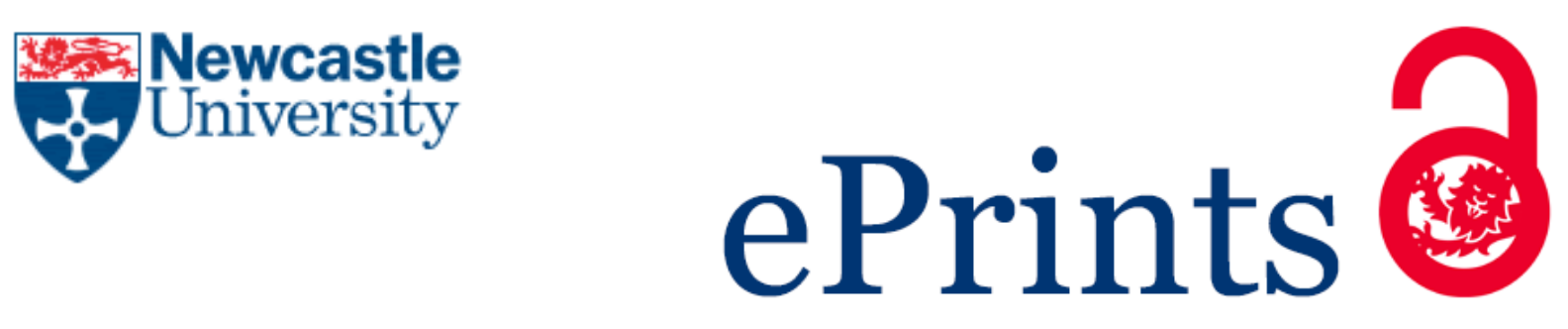

Yassin SA, German MJ, Rolland SL, Rickard AH, Jakubovics NS. Inhibition of multispecies biofilms by a fluoride-releasing dental prosthesis copolymer. Journal of Dentistry 2016, (ePub ahead of Print).

\title{
Copyright:
}

(C) 2016. This manuscript version is made available under the CC-BY-NC-ND 4.0 license

DOI link to article:

http://dx.doi.org/10.1016/j.jdent.2016.03.001

Date deposited:

$06 / 04 / 2016$

Embargo release date:

03 March 2017

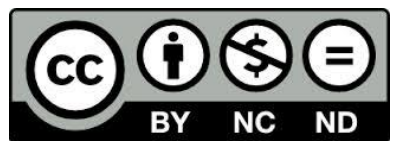

This work is licensed under a

Creative Commons Attribution-NonCommercial-NoDerivatives 4.0 International licence 


\section{Inhibition of multispecies biofilms by a fluoride-releasing dental}

\section{2 prosthesis copolymer}

\section{Abstract}

4 Objectives: This study aimed to develop a new mixed-species acidogenic biofilm model and use

5 it to assess the antimicrobial properties of a novel fluoride-releasing copolymer.

6 Methods: Stubs composed of a copolymer of methyl methacrylate (MMA) and 2-hydroxyethyl

7 methacrylate (HEMA) with polymethyl methacrylate (PMMA) were produced by chemically-

8 activated free radical polymerization. A fluoride-releasing copolymer was developed by

9 incorporating sodium fluoride in place of a portion of the PMMA. Samples were mounted in

10 polysulfone Modified Robbins Devices (MRDs) and were optimized for single- and mixed-species

11 biofilm formation by Candida albicans, Lactobacillus casei and Streptococcus mutans.

12 Results: Fluoride release was sustained for at least $48 \mathrm{~h}$ in flowing conditions. Fluoride did not

13 affect the colonization and biofilm growth of any of the microorganisms in monocultures.

14 However, in mixed-species biofilms, cell densities of all three species were reduced approximately

15 ten-fold $(\mathrm{p}<0.05)$ on the fluoridated material compared with the non-fluoridated copolymer.

16 Conclusions: These data demonstrate that intermicrobial interactions in mixed-species acidogenic

17 biofilms are sensitive to fluoride, and that the inclusion of fluoride in a denture lining copolymer

18 reduces the formation of polymicrobial biofilms.

19 Clinical Significance: The growth of acidogenic microorganisms on denture materials is associated

20 with denture stomatitis and dental caries on surrounding teeth. A fluoride-releasing copolymer that

21 inhibits acidogenic mixed-species biofilms, such as the material described in this study, has the

22 potential to control these diseases by limiting biofilm growth. 


\section{Introduction}

Dentures provide an artificial surface in the mouth that is susceptible to colonization by microbial biofilms. Denture plaque is somewhat similar in composition to dental plaque on tooth surfaces, although recent studies indicate that denture plaque has slightly lower species diversity and is enriched in Actinobacteria and Bacilli [1]. As denture plaque ages, proportions of acidogenic/aciduric microorganisms, including mutans streptococci, lactobacilli and Candida albicans tend to increase [2-6]. C. albicans is associated with denture stomatitis that presents in approximately $65 \%$ of edentulous individuals [7]. Furthermore, Candida species (especially $C$. albicans) are recognized as common colonizers of obturator prostheses, particularly in patients with dry mouth [8]. In addition to $C$. albicans, previous studies have indicated that bacteria including oral streptococci such as $S$. mitis, S. oralis, S. sanguinis, and S. mutans and lactobacilli (for example, L. casei) contribute to the development of oral appliance-related diseases including denture stomatitis and root caries [9-12]. There is some evidence that removable partial dentures (RPDs) also promote denture stomatitis [13]. Further, a strong link has been established between wearing an RPD and root caries [11].

Polymethyl methacrylate (PMMA) is a widely used denture base material for both partial and complete dentures [14]. This material is chosen for its good working characteristics, good esthetics, and low cost [15]. A number of previous studies have reported approaches to reduce biofilm formation on dentures by incorporating different materials into PMMA such as fillers, copolymers, and antimicrobials to minimize biofilm formation on the acrylic prosthesis [16]. Fluoride is particularly effective against cariogenic microorganisms, since it inhibits acid production as well as limiting the growth of certain microbes. In attempts to control dental caries, fluoride has been incorporated into a denture-coating material [17], and denture lining material [18]. However, these studies were focused on the physical and chemical properties of the materials and did not extend to assessing anti-caries activity or the abilities of the materials to control the growth of mixed-species acidogenic biofilms.

There is strong evidence that intermicrobial interactions play important roles in the development and stabilization of polymicrobial biofilms, including those that form in the human mouth [19-22]. Many different interkingdom interactions, for example between oral streptococci and Candida spp., have now been characterized in some detail [23]. Therefore, when modelling 
53 oral biofilms it is important to include mixed species of microorganisms in order to replicate some 54 of these interactions. Acidogenic microorganisms including mutans streptococci, lactobacilli and 55 C. albicans are particularly abundant on dentures in patients with denture stomatitis [2]. In 56 addition, there is evidence that increased numbers of $C$. albicans in denture biofilms are associated 57 with increases in lactobacilli [1]. Therefore, this work aimed to develop a novel mixed-species 58 model for culturing biofilms containing C. albicans, L. casei and S. mutans on acrylic materials 59 under flowing conditions. This model could then be employed to assess the antimicrobial 60 properties of a novel fluoride-releasing material consisting of a copolymer of methyl methacrylate 61 (MMA) and 2-hydroxyethyl methacrylate (HEMA) with polymethyl methacrylate (PMMA). This 62 material was originally developed for bonding orthodontic appliances [24], and for this study has 63 been modified to contain higher levels of fluoride. This fluoride-enhanced material offers potential 64 for clinical applications where control of acidogenic biofilms is important, for example denture 65 liners, obturators and surgical coverplates. 


\section{Materials and Methods}

\section{Copolymer sample preparation}

Cold cure acrylic resin (Wintercryl Rapid Repair; John Winter \& Co, Halifax, UK) was used, and $40 \%$ of the MMA was replaced by HEMA (Sigma Aldrich, St. Louis, USA). For the fluoridated copolymer, $30 \%$ of the PMMA was replaced by an equal mass of $\mathrm{NaF}$ (Sigma Aldrich).

73 The mixtures were transferred to custom-made plastic molds to produce either disc shapes for

74 fluoride measurements under static conditions or stubs of dimensions to fit the Modified Robbins Device (MRD), and allowed to set by chemically-activated free radical polymerization for $48 \mathrm{~h}$.

Fluoride release and recharge

Fluoride release from autoclaved samples was measured under static conditions or in some cases, from samples placed in the MRD under liquid flow. Fluoride was measured with an ion selective electrode (Orion Research, Thermo Scientific, MA, USA), after adding $500 \mu 1$ acetate buffer (TISAB III, Orion Research, MA, USA) to $5 \mathrm{ml}$ of the storage medium. For static conditions, five flat disc shaped samples of each copolymer were incubated independently in deionized water. Storage water was changed $24 \mathrm{~h}$ prior to measurements being taken and fluoride release over $24 \mathrm{~h}$ was determined by measuring the fluoride content in the water. For measurements of fluoride release under flowing conditions, a single stub was placed in the MRD system, and water was introduced at a rate of $40 \mathrm{ml} \mathrm{h}^{-1}$. Fluoride was measured in the effluent periodically up to $48 \mathrm{~h}$, and the experiment was repeated three times.

For fluoride recharging, freshly prepared fluoridated copolymer specimens were washed daily and placed into fresh water in order to take out as much fluoride possible from the material.

89 Before recharging, the daily fluoride release from all specimens was measured. Samples were 90 sonicated in deionized water containing $0.2 \% \mathrm{w} / \mathrm{v} \mathrm{NaF}$ for $3 \mathrm{~min}$ in an ultrasonic bath, rinsed with

91 distilled water, dried and incubated at $37^{\circ} \mathrm{C}$ in $5 \mathrm{ml}$ of fresh deionized water. Fluoride release was

92 measured daily for one week. Samples were incubated in deionized water for one further week and 93 the storage water changed $24 \mathrm{~h}$ prior to a second recharge cycle, to facilitate measurement of daily 94 fluoride release.

\section{Growth media and microbial culture}


Microbial strains used in this study were Candida albicans VPSA1 [25], L. casei ATCC334 and S. mutans UA159. C. albicans was cultured aerobically in Yeast Extract-Peptone-Dextrose (YPD) medium (Sigma-Aldrich) at $37^{\circ}$ C. L. casei was cultured in Rogosa medium (SigmaAldrich) in a candle jar at $37^{\circ} \mathrm{C}$, and $S$. mutans was cultured in Tryptone Yeast Cystine (TYC) medium (Sigma-Aldrich) supplemented with $20 \%$ (w/v) sucrose in a candle jar at $37^{\circ} \mathrm{C}$. Solidified media were prepared by adding $15 \mathrm{~g} \mathrm{~L}^{-1}$ Bacto-Agar (Difco, Oxford, UK). Artificial saliva [26] was employed for culturing organisms in the MRD, and sucrose was added as described below.

Standardised inocula were prepared for the MRD by culturing C. albicans, L. casei or $S$. mutans to mid-exponential phase, harvesting and re-suspending in one tenth volume of the appropriate growth medium supplemented with $25 \%$ (v/v) glycerol (Sigma-Aldrich). Cells were stored at $-80^{\circ} \mathrm{C}$, and an aliquot was removed for measuring total viable counts (TVCs) by the method of Miles and Misra [27]. Briefly, serial ten-fold dilutions were prepared in PBS (pH 7.4, Sigma-Aldrich) and triplicate $20 \mu \mathrm{l}$ aliquots were added to solidified media. C. albicans was incubated aerobically at $37^{\circ} \mathrm{C}$ for $24 \mathrm{~h}$, while L. casei or S. mutans were incubated at $37^{\circ} \mathrm{C}$ in a candle jar for $48 \mathrm{~h}$. Colonies were counted from dilutions that contained between 10-100 colonies.

111 For enumeration of individual species in mixed cultures, selective media were used as follows: 112 YPD, counted at $24 \mathrm{~h}$ for $C$. albicans; Rogosa Agar containing $21.6 \mu \mathrm{g} \mathrm{ml}^{-1}$ natamycin (Sigma113 Aldrich) for L. casei; and TYC Agar containing $21.6 \mu \mathrm{g} \mathrm{ml}^{-1}$ natamycin and $0.1 \mathrm{unit} \mathrm{ml}^{-1}$ bacitracin 114 (Sigma-Aldrich) for S. mutans.

\section{The Modified Robbins Device model biofilm system}

Two 12-port polysulfone MRDs (Tyler Research, Alberta, Canada) were assembled with 117 stubs of copolymer, sterilized by autoclaving for $15 \mathrm{~min}$ at $121^{\circ} \mathrm{C}$, and arranged in parallel at $37^{\circ} \mathrm{C}$

118 (Figure 1). Fluoridated copolymer stubs were included in one device, and control stubs (non119 fluoridated) in the other. To coat surfaces with human saliva, parafilm-stimulated saliva was 120 collected from six different volunteers who had not consumed food or drink other than water in 121 the previous hour and had not taken antibiotics in the previous three months. Dithiothreitol (Sigma122 Aldrich, St. Louis, Mo.) was added to a final concentration of $2.5 \mathrm{mM}$ and stirred gently on ice for $12310 \mathrm{~min}$. Samples were centrifuged at $15,000 \mathrm{~g}, 4^{\circ} \mathrm{C}$ for $30 \mathrm{~min}$ and filter sterilized. The MRD was 124 conditioned by the addition of $20 \mathrm{ml}$ saliva at a rate of $40 \mathrm{ml} \mathrm{h}^{-1}$ and inoculated with $1 \times 10^{5} C$. 125 albicans cells, $1 \times 10^{7} \mathrm{~L}$. casei cells, and/or $1 \times 10^{7} \mathrm{~S}$. mutans cells. Artificial saliva was then 
126 flowed through the model at $40 \mathrm{ml} \mathrm{h}^{-1}$. At time points up to $48 \mathrm{~h}$, stubs were removed and microbial 127 biofilms were recovered by scraping the surfaces into $1 \mathrm{ml}$ PBS (pH 7.4) or were prepared for 128 microscopy as detailed below. Measurements of $\mathrm{pH}$ were made using a Mettler Toledo S20 129 SevenEasy pH meter.

\section{Quantification of microorganisms by qPCR}

For enumeration of microorganisms by qPCR, DNA was extracted using the ZR

132 Fungal/Bacterial DNA extraction kit (Zymo Research Co., CA, USA). The following previously 133 published oligonucleotide primers and TaqMan probes were used to quantify bacterial biofilm 134 species: Smut3368-F, Smut3481-R, and Smut3423T [28] (for $S$. mutans, targeting the gtfB gene) 135 and L_case_IS, R_case_IS, and P_case_IS [29] (for L. casei, targeting the 16S-23S intergenic 136 region). For $C$. albicans VPSA1, the region surrounding the 5.8S rRNA gene was amplified by 137 PCR using primers CaFP1 5'-GGAACCGAGAAGCTGGTCAA-3' and CaRP1 5'138 GTCATCTCATCGCACGGGAT-3'. The PCR product was cleaned using the EZ-10 Spin Column 139 PCR Products Purification kit (NBS Biological, Huntingdon, UK), and sent for sequencing 140 (Eurofins Genomics, Ebersberg, Germany). The sequence was deposited in GenBank (accession

141 KJ39863). Based on this sequence, primers and TaqMan probe sequences for C. albicans were 142 adapted from [30], and were: CaFP2 5'GGAACCGAGAAGCTGGTCAA-3', CaRP2 5'143 GTCATCTCATCGCACGGGAT-3', Ca-probe 5'-TGAAGATATACGTGGTAGACGTTAG-

144 3'). The probe was modified with FAM-6 fluorescence reporter at the 5' end and MGBNFQ 145 fluorescence quencher at the 3' end.

146 Standards for qPCR were constructed by amplifying qPCR target regions from each microorganism. The amplified products were cloned in pCR2.1 (Invitrogen) to generate plasmids pTOPO-Ca, pTOPO-Lc and pTOPO-Sm, respectively, and used to transform E. coli TOP10 cells

149 (Invitrogen). Plasmids were extracted from E. coli using the Qiagen Plasmid Mini Kit, and 150 concentrations were determined by staining with Quant-i ${ }^{\mathrm{TM}}$ PicoGreen dsDNA Reagent and Kit 151 (Invitrogen). Amplification and detection of DNA by qPCR were performed with an Opticon 2 152 DNA Engine (Bio-Rad Laboratories Ltd., Hertfordshire, UK) using optical grade 96-well plates 153 (Eurogentec, Belgium). Quantitative PCR reactions were prepared, and contained the following 154 reagents in each well: forward primer (stock concentration, $2.5 \mu \mathrm{M}) 1.2 \mu \mathrm{L}$, reverse primer $(2.5$ $155 \mu \mathrm{M}) 1.2 \mu \mathrm{L}$, probe $(2.5 \mu \mathrm{M}) 0.6 \mu \mathrm{L}, 2 \mathrm{X}$ Takara master mix $7.5 \mu \mathrm{L}$ (Quantace, London, $\mathrm{UK}), \mathrm{H}_{2} \mathrm{O}$ 
3.3 $\mu \mathrm{L}$ and template DNA 1.0 $\mu \mathrm{L}$. The thermocycling conditions were as follows: initial denaturation at $95{ }^{\circ} \mathrm{C}$ for $2 \mathrm{~min}$, denaturation at $95{ }^{\circ} \mathrm{C}$ for $5 \mathrm{sec}$, annealing/extension at $60{ }^{\circ} \mathrm{C}$ for $30 \mathrm{sec}$, plate read and cycle repeated 40 times. All the reactions were carried out in triplicate and the final analysis was based on the mean of the three reactions. The qPCR data analysis was carried out using Opticon Monitor 3 software (MJ Research). The quantity of template DNA in each sample well was calculated by reference to wells containing serial 10-fold dilutions of standards of known DNA concentration and corrections were made for target sequence copy number based on the assumption that individual cells contained 110 copies of $C$. albicans ITS2 [31], 5 copies of L. casei 16S-23S rRNA [32], or 1 copy of S. mutans gtfB.

\section{Scanning electron microscopy (SEM)}

For SEM, samples were fixed in $2 \%(\mathrm{v} / \mathrm{v})$ glutaraldehyde at $4{ }^{\circ} \mathrm{C}$ for $16 \mathrm{~h}$, rinsed with PBS ( $\mathrm{pH} 7.4)$ and dehydrated through a series of ethanol washes as follows: $25 \%$ ethanol for $30 \mathrm{~min}$, $50 \%$ ethanol for $30 \mathrm{~min}, 75 \%$ ethanol for $30 \mathrm{~min}$, and two washes for $1 \mathrm{~h}$ in $100 \%$ ethanol. Samples were dried in a critical point dryer (Bal-tec, Reading, UK), mounted on aluminium stubs and sputter coated with gold at Electron Microscopy Research Services, Newcastle University. Biofilms were visualized using a Stereoscan 240 scanning electron microscope (Cambridge Instruments, Cambridge, UK).

\section{Confocal scanning laser microscopy (CSLM)}

For CSLM, the Live/Dead BacLight Bacterial Viability Kit (Life technologies Ltd, Paisley, UK) was used according to the manufacturer's instructions to stain single-species biofilms. Mixedspecies biofilms were stained with $50 \mu \mathrm{g} \mathrm{ml}^{-1}$ Alexa Fluor 488-conjugated Concanavalin A (ConA) (Life technologies Ltd, Paisley, UK), $5 \mu \mathrm{g} \mathrm{ml}^{-1}$ propidium iodide (Sigma Aldrich, St. Louis, USA) and $25 \mu \mathrm{g} \mathrm{ml}^{-1}$ 4',6-diamidino-2-phenylindole (DAPI) (Life technologies Ltd, Paisley, UK). Biofilms were examined and image stacks collected using a Leica TCS SP2 confocal laser scanning microscope with a x63 HCX PL APO oil immersion objective lens (numerical aperture 1.32) and an argon/neon laser for visualisation of SYTO 9 (excitation $488 \mathrm{~nm}$, emission $530 \mathrm{~nm}$ ), propidium iodide (excitation $530 \mathrm{~nm}$, emission $630 \mathrm{~nm}$ ), ConA (excitation $485 \mathrm{~nm}$, emission 519 $\mathrm{nm}$ ), and DAPI (excitation $358 \mathrm{~nm}$, emission $461 \mathrm{~nm}$ ). The collected image stacks of the biofilms were computationally rendered in three-dimensions using IMARIS Ver 7.3.1 software (Bitplane, 
Zurich, Switzerland) on a MSI PC computer (MSI computer corp, City of Industry, CA) equipped

186 with a Radeon HD5850 graphics card (AMD, Sunnyvale, CA).

$\underline{\text { Statistical analyses }}$

In each case, means and standard deviations were based on three independent biological experiments. Student's unpaired two-sample $T$ test was used for all statistical comparisons

190 between means and $p<0.05$ was considered statistically significant. Spearman's rank correlation

191 coefficients were calculated to assess correlations between qPCR and TVCs. All statistical tests

192 were performed in Sigmaplot (Systat Software Inc., San Jose, CA).

193 Results

194 Fluoride release from a fluoridated copolymer

195 In order to assess the stability of fluoride when introduced into the copolymer, fluoride

196 release was monitored under static conditions for 6 months (Figure 2). The rate of fluoride release 197 decayed approximately exponentially over this timeframe. High rates of release $198\left(>250 \mu \mathrm{g} / \mathrm{cm}^{2}\right.$.day) were sustained for 6 days and fluoride release was still detectable up to 1996 months, though at a much lower level. The release of fluoride from the copolymer was also 200 determined under flowing conditions in the MRD biofilm model by analyzing the fluoride 201 concentration in the effluent. Under these conditions, fluoride was released at $>90 \mu \mathrm{g} / \mathrm{cm}^{2}$.h for 2022 days (Figure 2 inset).

203 To assess the capacity of the PMMA material to recharge with fluoride, fluoridated PMMA 204 discs were first incubated in sterile distilled water for 30 days until the rate of release was $<10$ $205 \mu \mathrm{g} / \mathrm{cm}^{2}$.day. They were then recharged as describe in the Methods. One day after recharging, the 206 rate of fluoride release increased to $24 \mu \mathrm{g} / \mathrm{cm}^{2}$.day and release rates of $>10 \mu \mathrm{g} / \mathrm{cm}^{2}$.day were 207 sustained for 7 days (Figure 3). After a further period of washout for one week, the material was 208 recharged once again. After one day, fluoride release increased to $17 \mu \mathrm{g} / \mathrm{cm}^{2}$.day. Subsequently, 209 the rate of fluoride release reduced to $<10 \mu \mathrm{g} / \mathrm{cm}^{2}$.day (Figure 3). 
Optimization of qPCR for enumeration of microbial cells in mixed species biofilms

To monitor the growth of microorganisms in biofilms, targeted TaqMan qPCR assays were

212 developed for the specific enumeration of C. albicans, S. mutans, and L. casei. Initially, qPCR

213 techniques were compared with total viable counts (TVCs) for enumeration of microorganisms in

214 exponentially growing planktonic cultures. As shown in Figure 4, the qPCR assay for C. albicans

215 correlated well with TVCs $\left(\mathrm{R}^{2}=0.86\right)$ between $10^{4}$ and $10^{8}$ input cells. Cell counts were slightly

216 (approximately 1 order of magnitude) higher by qPCR than TVCs. There were also strong

217 correlations between TVCs and qPCR quantification for S. mutans $\left(\mathrm{R}^{2}=0.91\right)$ and L. casei $\left(\mathrm{R}^{2}=\right.$

218 0.91) (Figure 4B and 4C). For $S$. mutans, cell counts were < 1 order of magnitude higher by qPCR

219 than by TVCs, whereas in the case of L. casei, cell counts were 2-3 orders of magnitude higher by

220 qPCR than by TVCs. The lower limit of C. albicans was around $10^{3}-10^{4}$ cells, S. mutans could be 221 detected down to $10^{4}$ cells, and $L$. casei could be detected at $>10^{3}$ cells. Below these levels, the 222 relationship between qPCR counts and TVCs appeared to break down (indicated by red squares in 223 Figure 4).

\section{Impact of fluoride release on single species biofilms}

In monoculture, $C$. albicans and $L$. casei grew in artificial saliva with sucrose added three times per day to form diffuse biofilms on saliva-conditioned copolymer (Figure 5). S. mutans grew well in medium supplemented with $1 \%(\mathrm{w} / \mathrm{v})$ sucrose and formed biofilms consisting of aggregated microcolonies (Figure 5). Extracellular material was observed in biofilms of each microorganism by SEM (Figure 5A and data not shown). Single species biofilms were also cultured in the MRD

231 on fluoridated copolymer stubs. Total counts of each microorganism, determined by qPCR, were 232 not significantly different on the two types of surface, indicating that fluoride did not reproducibly 233 inhibit the growth of monospecies biofilms (Figure 5B).

\section{Effects of fluoridated copolymer on mixed species biofilms}

To assess the impact of fluoride release from copolymer on the composition and biomass of mixed-species biofilms, C. albicans, L. casei and S. mutans were co-cultured in parallel MRD

238 chambers containing samples of fluoridated copolymer or non-fluoridated substrata. All three 
species grew in biofilms formed in artificial saliva supplemented with $0.1 \%(\mathrm{w} / \mathrm{v})$ sucrose and

240 could be distinguished within microcolonies by SEM (Figure 6A). On non-fluoridated copolymer,

241 numerous $C$. albicans yeast cells, hyphae and pseudohyphae were observed interacting with

242 bacteria and producing large microbial aggregates. By contrast, biofilms on fluoridated surfaces

243 were relatively thin, sparsely distributed, and microbial cells were often restricted to pits within

244 the acrylic material (Figure 6B).

245 To distinguish between $C$. albicans and bacteria more clearly and to obtain three246 dimensional images without dehydration artefacts, mixed-species biofilms were also imaged by 247 CSLM. C. albicans hyphae could be clearly distinguished from bacterial cells (Figure 6C and D). 248 Bacteria in particular were clearly more abundant on non-fluoridated surfaces than on fluoride249 releasing copolymer. Quantification of cells by qPCR demonstrated significant reductions in all 250 three microorganisms on fluoridated surfaces compared with non-fluoridated copolymer after $48 \mathrm{~h}$ 251 (Student's T test, $\mathrm{p}<0.05$; Figure 6E). To determine whether the reduction in cell numbers on 252 fluoridated surfaces was associated with the capacity of fluoride to inhibit acid production, the $\mathrm{pH}$ 253 of the effluent from the MRD was measured during biofilm formation. After $24 \mathrm{~h}$, the $\mathrm{pH}$ from 254 mixed-species biofilms had reduced from $6.99( \pm 0.03)$ to $4.38( \pm 0.02)$ on non-fluoridated 255 surfaces and to $4.47( \pm 0.04)$ on fluoridated material. These values were significantly different 256 (Student's T test, $\mathrm{p}<0.05$ ). By $48 \mathrm{~h}$, the $\mathrm{pH}$ from biofilms on non-fluoridated copolymer was 4.32 $257( \pm 0.01)$, and the $\mathrm{pH}$ from fluoridated copolymer was $4.35( \pm 0.05)(\mathrm{p}>0.05)$.

\section{Discussion}

Problems arising from plaque on removable prostheses, including denture stomatitis and 261 root caries, are associated with an overgrowth of acidogenic and aciduric microorganisms [2]. 262 Fluoride inhibits acid production and, at an appropriate concentration, can limit the growth of 263 acidogenic microorganisms [33]. Potentially, the prolonged release of fluoride from an acrylic 264 material could have long-term benefits in controlling the establishment of an acidogenic microbial 265 community in the oral cavity. An ideal material needs to release fluoride at a relatively constant 266 rate over a sustained period, and should have the capacity to be recharged periodically with 267 fluoride. This material could be used to line prostheses in contact with caries-susceptible sites for 
example overdenture abutments or to construct appliances such as surgical coverplates which are used short term but are difficult to clean.

We chose to incorporate fluoride in the form of $\mathrm{NaF}$, since the release of $\mathrm{NaF}$ from materials is relatively stable across a range of $\mathrm{pH}$ values [34]. The addition of HEMA facilitates

272 the sustained release of fluoride by promoting the diffusion of water [24]. In line with previous 273 studies [17, 24], under static conditions fluoride was released at a relatively high rate initially, 274 followed by a gradually decreasing rate of release. Even after six months, fluoride release was in 275 the range of $12-15 \mu \mathrm{g} / \mathrm{cm}^{2}$.day. Although we did not measure the fluoride concentration in the 276 immediate vicinity of the disc, it is likely that this sustained release of fluoride will have significant 277 effects on dental plaque bacteria in the base of a biofilm formed on the resin. Dental plaque can 278 retard the diffusion of fluoride and therefore the thickness of the plaque present will affect the local 279 concentration of fluoride achieved [35]. As little as $10 \mathrm{mg} \mathrm{L}^{-1}$ fluoride inhibits acid production by 280 dental plaque [36, 37]. In the MRD biofilm model, which is a flowing system that will continually 281 wash away dissolved fluoride, high levels of fluoride release were sustained for at least $48 \mathrm{~h}$. 282 Although fluoride will eventually be washed out of the copolymer, it was found that the material 283 has the potential to be recharged. Here, recharging with fluoride was achieved using sonication for $2843 \mathrm{~min}$ in a water bath. Further studies are needed to assess recharging characteristics under 285 conditions that might be achieved in a home environment, for example by soaking for a defined 286 period in a fluoride solution.

The Modified Robbins Device (MRD) was employed to culture biofilms since it is a wellestablished model system that can hold stubs of material flush against the wall of the vessel with minimal turbulent flow [38]. Initially, biofilms were cultured on non-fluoridated copolymer in

290 artificial saliva medium, supplemented with $10 \%$ (w/v) sucrose three times daily to mimic meals.

291 Although C. albicans and L. casei grew well in monoculture under these conditions, it was not 292 possible to obtain reproducible biofilms of $S$. mutans. Therefore, for $S$. mutans monoculture 293 experiments, $1 \%$ sucrose was introduced continuously. These observations indicate that $S$. mutans 294 is highly dependent on sucrose for biofilm formation in monoculture under flowing conditions, as 295 has been demonstrated previously in batch culture [39]. Interestingly, when mixed-species 296 biofilms were cultured in medium containing $1 \%$ sucrose, the production of polysaccharide was 297 so great that it blocked the tubing and interfered with the running of the system. Therefore, the 
$\underline{\text { sucrose concentration was reduced to } 0.1 \% \text { in order to culture mixed-species biofilms. It appears }}$

299 that exopolysaccharide production occurs to a greater extent in mixed-species biofilms than in

300 single-species $S$. mutans biofilms, possibly as a result of sucrose utilization by C. albicans [40]. It

301 is not yet clear to what extent exopolysaccharide production is modulated by intermicrobial

302 interactions between the three organisms, although it has been shown that L. casei induces down-

303 regulation of $g t f B$, encoding glucosyltransferase B, in S. mutans [41].

When introducing chemically modified surfaces into a biofilm model, it is important that sterilization of surfaces does not affect the chemical or physical properties of the substratum. Using Fourier Transform Infrared (FTIR) spectroscopy, it was found that the sample stubs did not undergo chemical changes during autoclaving in the system (data not shown). There was a slight increase in the average roughness $\left(\mathrm{R}_{\mathrm{a}}\right)$ of the fluoridated copolymer after autoclaving, measured by stylus profilometry $\left(\mathrm{R}_{\mathrm{a}}=3.49 \pm 0.90 \mu \mathrm{m}\right.$ after autoclaving compared with $2.77 \pm 0.91 \mu \mathrm{m}$ before autoclaving). Using SEM, small pits were seen in the autoclaved fluoridated copolymer (data not

311 shown). Some of these pits appeared to harbor microorganisms (Figure 6B). Nevertheless, when

312 biofilms were developed with single species of microorganisms, there were no significant

313 differences in biofilm growth over $48 \mathrm{~h}$ on fluoridated or non-fluoridated copolymer.

Even though single species biofilms were apparently unaffected by fluoride release from

315 the copolymer, biofilm formation by a mixed species community of oral acidogenic

316 microorganisms was significantly reduced approximately 10-fold in the presence of fluoride.

317 Therefore, it appears that fluoride interferes with a critical factor involved in intermicrobial

318 interactions rather than inhibiting individual species directly. Recent research has shown that oral

319 bacteria communicate with one another and with oral Candida spp., and that these interactions are

320 critical for biofilm development [42-44]. It is possible that fluoride interferes with some aspect of

321 cell-cell communication, and that this destabilizes mixed-species biofilms. Synergistic interactions

322 between $C$. albicans and oral bacteria have been documented that appear to depend on physical

323 cell-cell binding (coaggregation) and/or metabolic cooperation, and these processes may also be

324 targets of the action of fluoride $[45,46]$. In fact, it is likely that fluoride inhibits carbohydrate

325 metabolism and acid generation with mixed-species biofilms since fluoride is well-known to

326 inhibit sugar uptake and glycolysis [47, 48]. Although there was a significant reduction in acid

327 production by biofilms on non-fluoridated versus fluoridated copolymer after $24 \mathrm{~h}$, no significant 
328 differences between the $\mathrm{pH}$ in the effluent from biofilms on the different surfaces were seen at $32948 \mathrm{~h}$. These data indicate that the inhibitory effects of fluoride on acidogenicity may be most 330 important during the early stages of biofilm formation. However, it would be interesting to 331 determine the $\mathrm{pH}$ in the local microenvironment within biofilms, for example by using $\mathrm{pH}-$ 332 sensitive fluorescent dyes [49]. Even in the presence of fluoride, mixed-species biofilms acidified 333 the medium to below the critical pH for enamel dissolution [50]. Within more complex microbial 334 communities, it is likely that other species may offset the $\mathrm{pH}$ reductions by catabolizing lactic acid 335 [51] or by producing ammonia from arginine or urea [52]. In these more complex communities, it 336 has been shown that fluoride can shift the ecological balance and prevent the overgrowth of 337 strongly acidogenic microorganisms such as S. mutans [53]. Therefore, we are now aiming to 338 investigate the potential of the fluoridated copolymer to reduce the growth of acidogenic microorganisms within dental plaque communities that more closely resemble those found in the 340 human mouth.

In this study, enumeration of microorganisms was achieved by qPCR. This approach will 342 detect total DNA from each species, which is derived from live and dead cells. To ensure the 343 validity of the qPCR approach when applied to biofilm samples, viable cells of each species were 344 also enumerated on selective media (data not shown). Generally, qPCR tends to give higher counts 345 than TVCs [54] and, in line with this, absolute counts of L. casei and S. mutans in samples from 346 biofilms were consistently 2-3 orders of magnitude higher by qPCR than by TVCs. For C. albicans 347 the two techniques gave similar cell counts when applied to biofilm cells (data not shown). It 348 should be noted that both methods have limitations. Viable counts depend on efficient recovery of 349 cells from biofilms and dispersal of aggregated microorganisms. Various hyphal and budding 350 forms of $C$. albicans were observed by SEM and CSLM that were not well-separated, and would 351 have resulted in an underestimation of cell numbers by TVCs. The qPCR method depends on 352 disruption of thick fungal cell walls that are not easily lysed [55]. Therefore, qPCR may also have 353 underestimated $C$. albicans cell numbers. Nevertheless, when the two methods were employed to 354 assess growth reductions on fluoridated surfaces, both techniques gave similar trends. Importantly, 355 statistically significant reductions in all three species within mixed biofilms on fluoride-releasing 356 copolymer were observed by both qPCR and TVCs. 


\section{Conclusions}

359 In conclusion, a novel fluoride-releasing copolymer has been developed that inhibits the 360 growth of mixed-species acidogenic oral biofilms in vitro. Biofilm inhibition was apparent for 361 mixed-species cultures but not for single-species biofilms, indicating that fluoride may interfere 362 with interspecies or interkingdom cell-cell interactions. Further work is required to elucidate the

363 mechanism by which fluoride inhibits mixed-species biofilm development. Ultimately, this study 364 demonstrates the potential for a fluoride-releasing copolymer to control mixed-species oral 365 biofilms and provides a foundation for future clinical investigations. 


\section{References}

367 [1] O'Donnell LE, Robertson D, Nile CJ, Cross LJ, Riggio M, Sherriff A, et al. The oral

368 microbiome of denture wearers is influenced by levels of natural dentition. PLoS One, 10 (2015) $369 \mathrm{e} 0137717$.

370 [2] Mantzourani M, Gilbert SC, Fenlon M, Beighton D. Non-oral bifidobacteria and the aciduric 371 microbiota of the denture plaque biofilm. Mol. Oral Microbiol., 25 (2010) 190-9.

372 [3] Budtz-Jörgensen E. The significance of Candida albicans in denture stomatitis. Scand. J. 373 Dent. Res., 82 (1974) 151-90.

374 [4] Koopmans AS, Kippuw N, de Graaff J. Bacterial involvement in denture-induced stomatitis. 375 J. Dent. Res., 67 (1988) 1246-50.

376 [5] Sumi Y, Kagami H, Ohtsuka Y, Kakinoki Y, Haruguchi Y, Miyamoto H. High correlation 377 between the bacterial species in denture plaque and pharyngeal microflora. Gerodontology, 20 378 (2003) 84-7.

379 [6] Theilade E, Budtz-Jorgensen E, Theilade J. Predominant cultivable microflora of plaque on 380 removable dentures in patients with healthy oral mucosa. Arch. Oral Biol., 28 (1983) 675-80. 381 [7] Chandra J, Kuhn DM, Mukherjee PK, Hoyer LL, McCormick T, Ghannoum MA. Biofilm 382 formation by the fungal pathogen Candida albicans: development, architecture, and drug 383 resistance. J. Bacteriol., 183 (2001) 5385-94.

384 [8] Murakami M, Nishi Y, Seto K, Kamashita Y, Nagaoka E. Dry mouth and denture plaque 385 microflora in complete denture and palatal obturator prosthesis wearers. Gerodontology, 32 386 (2015) 188-94.

387 [9] Sato M, Tsuchiya H, Akagiri M, Takagi N, Iinuma M. Growth inhibition of oral bacteria 388 related to denture stomatitis by anti-candidal chalcones. Aust. Dent. J., 42 (1997) 343-6.

389 [10] Morgan TD, Wilson M. Anti-adhesive and antibacterial properties of a proprietary denture 390 cleanser. J. Appl. Microbiol., 89 (2000) 617-23.

391 [11] Preshaw PM, Walls AW, Jakubovics NS, Moynihan PJ, Jepson NJ, Loewy Z. Association 392 of removable partial denture use with oral and systemic health. J. Dent., 39 (2011) 711-9.

393 [12] Teles FR, Teles RP, Sachdeo A, Uzel NG, Song XQ, Torresyap G, et al. Comparison of 394 microbial changes in early redeveloping biofilms on natural teeth and dentures. J. Periodontol., $39583(2012) 1139-48$. 
[13] Emami E, Taraf H, de Grandmont P, Gauthier G, de Koninck L, Lamarche C, et al. The association of denture stomatitis and partial removable dental prostheses: a systematic review. Int. J. Prosthodont., 25 (2012) 113-9. [14] Chen S-Y, Liang W-M, Yen P-S. Reinforcement of acrylic denture base resin by incorporation of various fibers. J. Biomed. Mater. Res., 58 (2001) 203-08. [15] John J, Gangadhar SA, Shah I. Flexural strength of heat-polymerized polymethyl methacrylate denture resin reinforced with glass, aramid, or nylon fibers. J. Prosthet. Dent., 86 403 (2001) 424-7.

404 [16] Raj PA, Dentino AR. Denture polymers with antimicrobial properties: a review of the 405 development and current status of anionic poly(methyl methacrylate) polymers. Future Med. 406 Chem., 5 (2013) 1635-45.

407 [17] Kodkeaw P, Phankosol P, Jiratumnukul N. Light cured fluoride filled denture-coating 408 materials. J. Appl. Polym. Sci., 116 (2010) 743-47.

409 [18] Hayakawa I, Akiba N, Keh E, Kasuga Y. Physical properties of a new denture lining 410 material containing a fluoroalkyl methacrylate polymer. J. Prosthet. Dent., 96 (2006) 53-58. 411 [19] Jakubovics NS. Talk of the town: interspecies communication in oral biofilms. Mol. Oral 412 Microbiol., 25 (2010) 4-14.

413 [20] Jakubovics NS, Yassin SA, Rickard AH. Community interactions of oral streptococci. Adv. 414 Appl. Microbiol., 87 (2014) 43-110.

415 [21] Kolenbrander PE, Palmer RJ, Jr., Periasamy S, Jakubovics NS. Oral multispecies biofilm 416 development and the key role of cell-cell distance. Nat. Rev. Microbiol., 8 (2010) 471-80.

417 [22] Wright CJ, Burns LH, Jack AA, Back CR, Dutton LC, Nobbs AH, et al. Microbial 418 interactions in building of communities. Mol. Oral Microbiol., 28 (2013) 83-101.

419 [23] Xu H, Jenkinson HF, Dongari-Bagtzoglou A. Innocent until proven guilty: mechanisms and 420 roles of Streptococcus-Candida interactions in oral health and disease. Mol. Oral Microbiol., 29 421 (2014) 99-116.

422 [24] Su L, Bai Y, Li S, Al-Naimi OT, McCabe JF. A new acrylic-based fluoride-releasing 423 cement as a potential orthodontic bonding agent. Acta Odontol. Scand., 68 (2010) 207-14. 424 [25] Shakir A, ElBadawey MR, Shields RC, Jakubovics NS, Burgess JG. Removal of biofilms 425 from tracheoesophageal speech valves using a novel marine microbial deoxyribonuclease. 426 Otolaryngol. Head Neck Surg., 147 (2012) 509-14. 
427 [26] Pratten J, Smith A, Wilson M. Response of single species biofilms and microcosm dental 428 plaques to pulsing with chlorhexidine. J. Antimicrob. Chemother., 42 (1998) 453-59.

429 [27] Miles A, Misra S, Irwin J. The estimation of the bactericidal power of the blood. J. Hyg. 430 (Lond.), 38 (1938) 732-49.

431 [28] Yoshida A, Suzuki N, Nakano Y, Kawada M, Oho T, Koga T. Development of a 5' 432 nuclease-based real-time PCR assay for quantitative detection of cariogenic dental pathogens 433 Streptococcus mutans and Streptococcus sobrinus. J. Clin. Microbiol., 41 (2003) 4438-41.

434 [29] Haarman M, Knol J. Quantitative real-time PCR analysis of fecal Lactobacillus species in 435 infants receiving a prebiotic infant formula. Appl. Environ. Microbiol., 72 (2006) 2359-65.

436 [30] Guiver M, Levi K, Oppenheim BA. Rapid identification of Candida species by TaqMan 437 PCR. J. Clin. Pathol., 54 (2001) 362-66.

438 [31] Jones T, Federspiel NA, Chibana H, Dungan J, Kalman S, Magee B, et al. The diploid 439 genome sequence of Candida albicans. Proc. Natl. Acad. Sci. U. S. A., 101 (2004) 7329-34. 440 [32] Stoddard SF, Smith BJ, Hein R, Roller BR, Schmidt TM. rrnDB: improved tools for 441 interpreting rRNA gene abundance in bacteria and archaea and a new foundation for future 442 development. Nucleic Acids Res., 43 (2015) D593-8.

443 [33] Nakajo K, Imazato S, Takahashi Y, Kiba W, Ebisu S, Takahashi N. Fluoride released from 444 glass-ionomer cement is responsible to inhibit the acid production of caries-related oral 445 streptococci. Dent. Mater., 25 (2009) 703-08.

446 [34] Shen C, Shokry T, Anusavice K. Influence of pH and oxygen-inhibited layer on fluoride 447 release properties of fluoride sealant. J. Dent., 35 (2007) 275-81.

448 [35] Watson P, Pontefract H, Devine D, Shore R, Nattress B, Kirkham J, et al. Penetration of 449 fluoride into natural plaque biofilms. J. Dent. Res., 84 (2005) 451-55.

450 [36] Bibby B, Fu J. Effects of fluorides on in vitro acid production by dental plaque. J. Dent. 451 Res., 65 (1986) 686-88.

452 [37] Jenkins G, Edgar W, Ferguson D. The distribution and metabolic effects of human plaque 453 fluorine. Arch. Oral Biol., 14 (1969) 105-19.

454 [38] Honraet K, Nelis HJ. Use of the modified robbins device and fluorescent staining to screen 455 plant extracts for the inhibition of S. mutans biofilm formation. J. Microbiol. Methods, 64 (2006) 456 217-24. 
[39] Duarte S, Klein MI, Aires CP, Cury JA, Bowen WH, Koo H. Influences of starch and

458 sucrose on Streptococcus mutans biofilms. Oral Microbiol. Immunol., 23 (2008) 206-12.

459 [40] Gonçalves LM, Del Bel Cury AA, de Vasconcellos AA, Cury JA, da Silva WJ. Confocal

460 analysis of the exopolysaccharide matrix of Candida albicans biofilms. J. Investig. Clin. Dent., 6 461 (2015) 179-85.

462 [41] Wen ZT, Yates D, Ahn SJ, Burne RA. Biofilm formation and virulence expression by 463 Streptococcus mutans are altered when grown in dual-species model. BMC Microbiol., 10 $464 \quad$ (2010) 111.

465 [42] Falsetta ML, Klein MI, Colonne PM, Scott-Anne K, Gregoire S, Pai C-H, et al. Symbiotic 466 Relationship between Streptococcus mutans and Candida albicans Synergizes Virulence of 467 Plaque Biofilms In Vivo. Infect. Immun., 82 (2014) 1968-81.

468 [43] Thein ZM, Samaranayake YH, Samaranayake LP. Effect of oral bacteria on growth and 469 survival of Candida albicans biofilms. Arch. Oral Biol., 51 (2006) 672-80.

470 [44] Jarosz LM, Deng DM, van der Mei HC, Crielaard W, Krom BP. Streptococcus mutans 471 competence-stimulating peptide inhibits Candida albicans hypha formation. Eukaryot. Cell, 8 472 (2009) 1658-64.

473 [45] Cavalcanti IM, Del Bel Cury AA, Jenkinson HF, Nobbs AH. Interactions between 474 Streptococcus oralis, Actinomyces oris, and Candida albicans in the development of 475 multispecies oral microbial biofilms on salivary pellicle. Mol Oral Microbiol, (2016).

476 [46] Cavalcanti IM, Nobbs AH, Ricomini-Filho AP, Jenkinson HF, Del Bel Cury AA.

477 Interkingdom cooperation between Candida albicans, Streptococcus oralis and Actinomyces oris 478 modulates early biofilm development on denture material. Pathog Dis, 74 (2016).

479 [47] Van Loveren C. The antimicrobial action of fluoride and its role in caries inhibition. J. Dent. 480 Res., 69 Spec No (1990) 676-81.

481 [48] Hamilton I, Ellwood D. Effects of fluoride on carbohydrate metabolism by washed cells of 482 Streptococcus mutans grown at various pH values in a chemostat. Infect. Immun., 19 (1978) 43448342.

484 [49] Xiao J, Klein MI, Falsetta ML, Lu B, Delahunty CM, Yates JR, 3rd, et al. The 485 exopolysaccharide matrix modulates the interaction between 3D architecture and virulence of a 486 mixed-species oral biofilm. PLoS Pathog., 8 (2012) e1002623.

487 [50] Bowen WH. The Stephan Curve revisited. Odontology, 101 (2013) 2-8. 
488 [51] Do T, Sheehy EC, Mulli T, Hughes F, Beighton D. Transcriptomic analysis of three

489 Veillonella spp. present in carious dentine and in the saliva of caries-free individuals. Front Cell

490 Infect Microbiol, 5 (2015) 25.

491 [52] Huang X, Palmer S, Ahn SJ, Richards VP, Williams ML, Nascimento MM, et al.

492 Characterization of a highly arginolytic Streptococcus species that potently antagonizes

493 Streptococcus mutans. Appl. Environ. Microbiol., In press (2016) DOI: 10.1128/AEM.03887-15.

494 [53] Marsh PD, Bradshaw DJ. The effect of fluoride on the stability of oral bacterial

495 communities in vitro. J. Dent. Res., 69 Spec No (1990) 668-71.

496 [54] Childers NK, Osgood RC, Hsu K-L, Manmontri C, Momeni SS, Mahtani HK, et al. Real-

497 time quantitative polymerase chain reaction for enumeration of Streptococcus mutans from oral

498 samples. Eur. J. Oral Sci., 119 (2011) 447-54.

499 [55] Cryer D, Eccleshall R, Marmur J. Isolation of yeast DNA. Methods Cell Biol., 12 (1976)

$500 \quad 39-44$.

501

502 


\section{Figure legends}

505 Figure 1. Design of the MRD biofilm system. Biofilms are formed on copolymer pieces held 506 within a plug and flush against the wall of the vessel. The samples were conditioned with natural 507 saliva, and then inoculum was introduced. Artificial saliva and sucrose were added as required. 508 The flow of liquid was controlled using clamps and a peristaltic pump.

Figure 2. Fluoride release from fluoridated copolymer material, Teflon moulds were used to

511 prepare discs of $10 \mathrm{~mm}$ diameter and $1 \mathrm{~mm}$ thickness. Fluoride release under static incubation (A) 512 gradually declined over the 6 month period. The release of fluoride was also monitored in flowing 513 conditions, using samples held in the MRD for $48 \mathrm{~h}$ (B). In the latter case, fluoride was only 514 released from the exposed surface of the stub. Bars show mean values and standard deviations 515 from five discs of each sample (static model) or three independent experiments (MRD model).

517 Figure 3. Fluoride recharge and release. Samples were recharged by bathing for 3 min in $0.2 \%$ $518 \mathrm{NaF}$ in an ultrasonic bath at day 0 and day 14. The first measurement after recharging is marked 519 with a dashed line. Bars represent means of five samples and standard deviations are shown.

521 Figure 4. Correlations between cell counts measured as TVC's or by qPCR. Dilutions of cells 522 were prepared from mid-logarithmic cultures of C. albicans, L. casei or S. mutans. Cell numbers 523 quantified by TVC's were compared with numbers from qPCR assays. At low cell numbers, the 524 relationships between qPCR counts and TVCs appeared to break down (red squares highlighted 525 within circles), indicating the lower limits of sensitivity of the qPCR assay. These data were not 526 included for calculation of the trendline. 
528 Figure 5. Single species biofilm formation by three microorganisms on non-fluoridated material 529 after 48 h. (A) Biofilms of C. albicans, L. casei and S. mutans were visualized by SEM. Note that 530 C. albicans and L. casei were cultured in artificial saliva pulsed three times daily with $10 \%$ sucrose, 531 whereas S. mutans was cultured in artificial saliva supplemented with $1 \%$ sucrose throughout 532 growth. In each case, extensive biofilms were observed and cell clusters, or microcolonies, could 533 clearly be seen. (B) Cell numbers in biofilms developed in the MRD control samples (dark bars) 534 or fluoridated copolymer (light bars) were enumerated by qPCR and expressed as genome 535 equivalents $(\mathrm{GE}) / \mathrm{cm}^{2}$ of acrylic surface area. Bars represent means and standard deviations from 536 three independent experiments. A lower cell density of $C$. albicans was used to inoculate the MRD

537 biofilm model than L. casei or S. mutans and total counts of C. albicans were relatively low after $53848 \mathrm{~h}$ (presented as an inset graph as there is a different scale on the y axis). Overall, there were no significant differences in cell counts of any species on control or fluoridated samples.

542 Figure 6. Mixed species biofilm formation after 48 h on non-fluoridated material after 48 h. (A) 543 Biofilm microcolonies were visible across the surface of control copolymer samples (arrows). At 544 high magnification (inset), C. albicans and bacteria were seen to be closely interacting within these 545 biofilms. (B) On fluoridated samples, surface coverage was reduced, and in places growth was 546 restricted to pits within the material (arrow). Biofilms on control (C) or fluoridated (D) copolymer 547 were also visualized by CSLM. Samples were stained with propidium iodide (red) and DAPI (blue) 548 to highlight bacterial cells (appear purple), and ConA (green), which labels fungal cell walls 549 including C. albicans. (E) Cells were removed from surfaces at different times after inoculating 550 the MRD biofilm model and each species in biofilms on control samples (dark bars) and 551 fluoridated samples (light bars) enumerated by qPCR. Bars represent mean values and standard 552 deviations from three independent experiments. In all cases, cell counts on fluoridated material $55348 \mathrm{~h}$ after inoculation were significantly lower than on non-fluoridated copolymer, as indicated by 554 an asterisk (Student's T-test, $p<0.05$ ). 
Figure 1

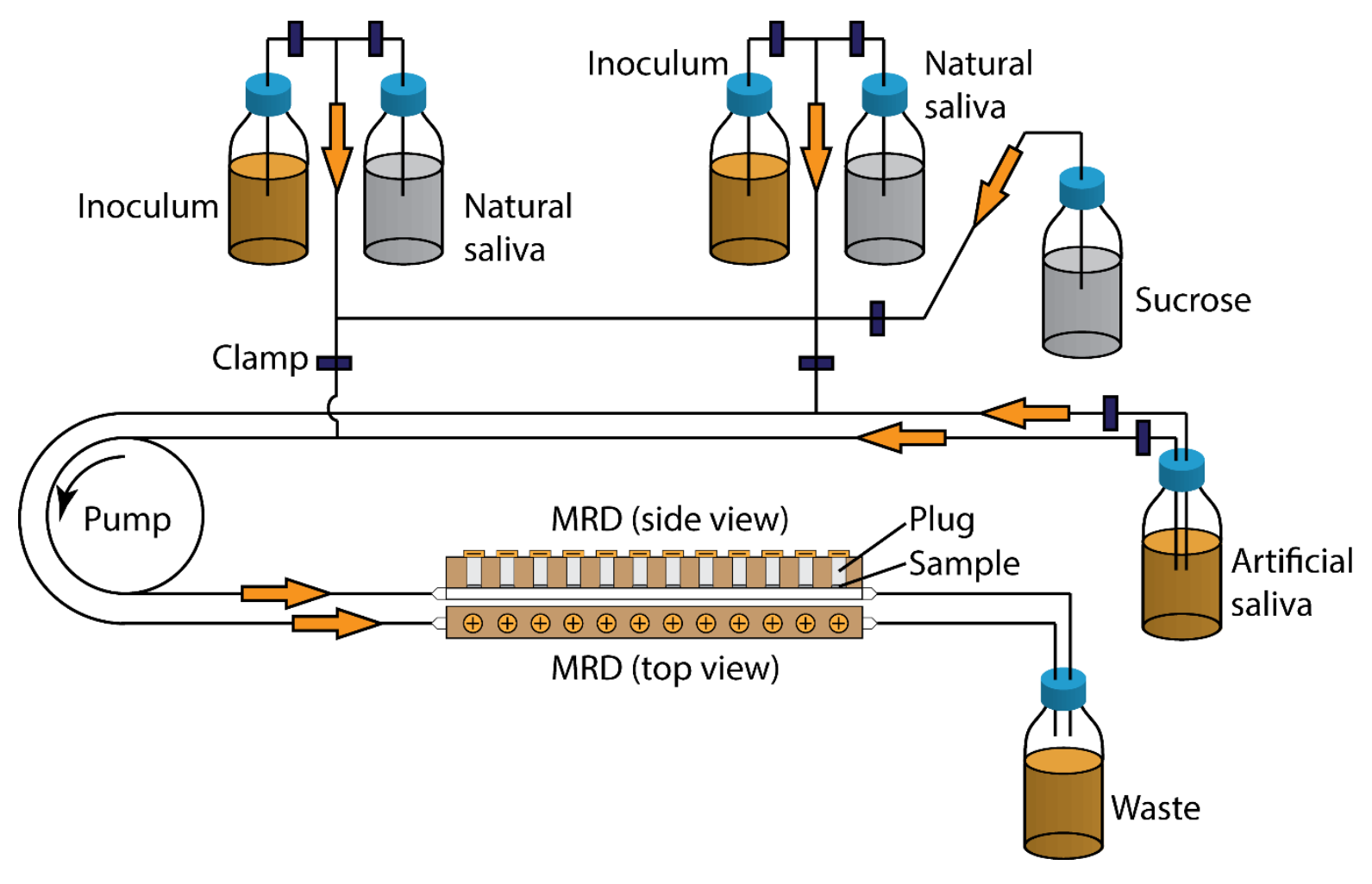


Figure 2
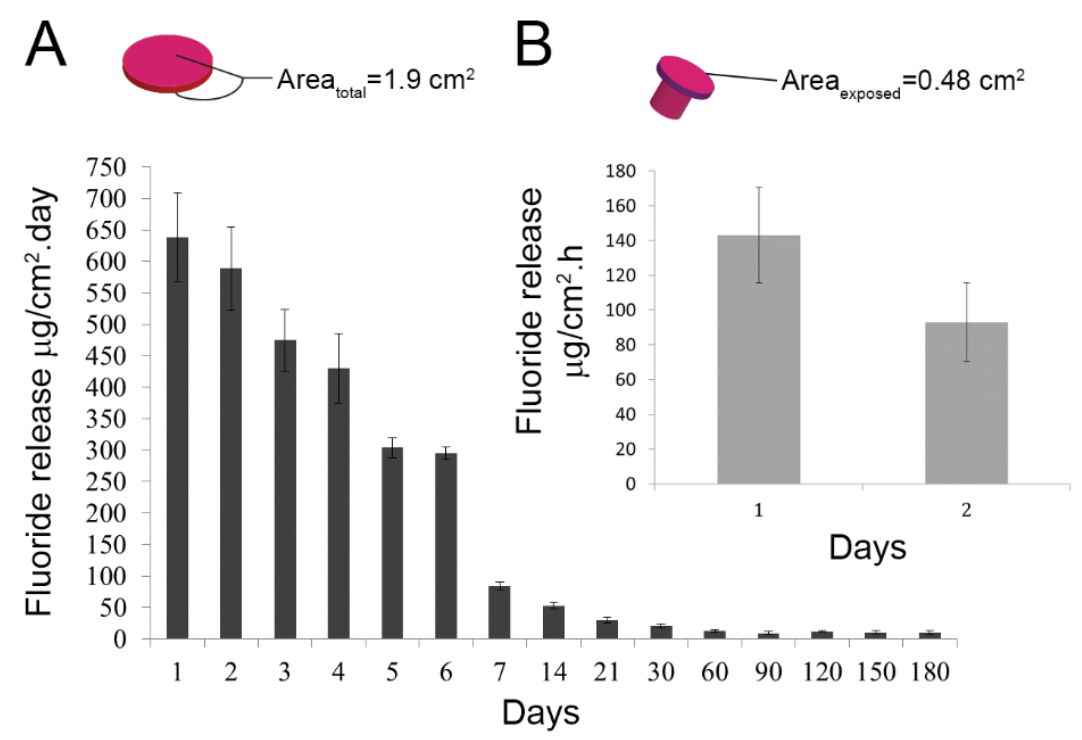
Figure 3

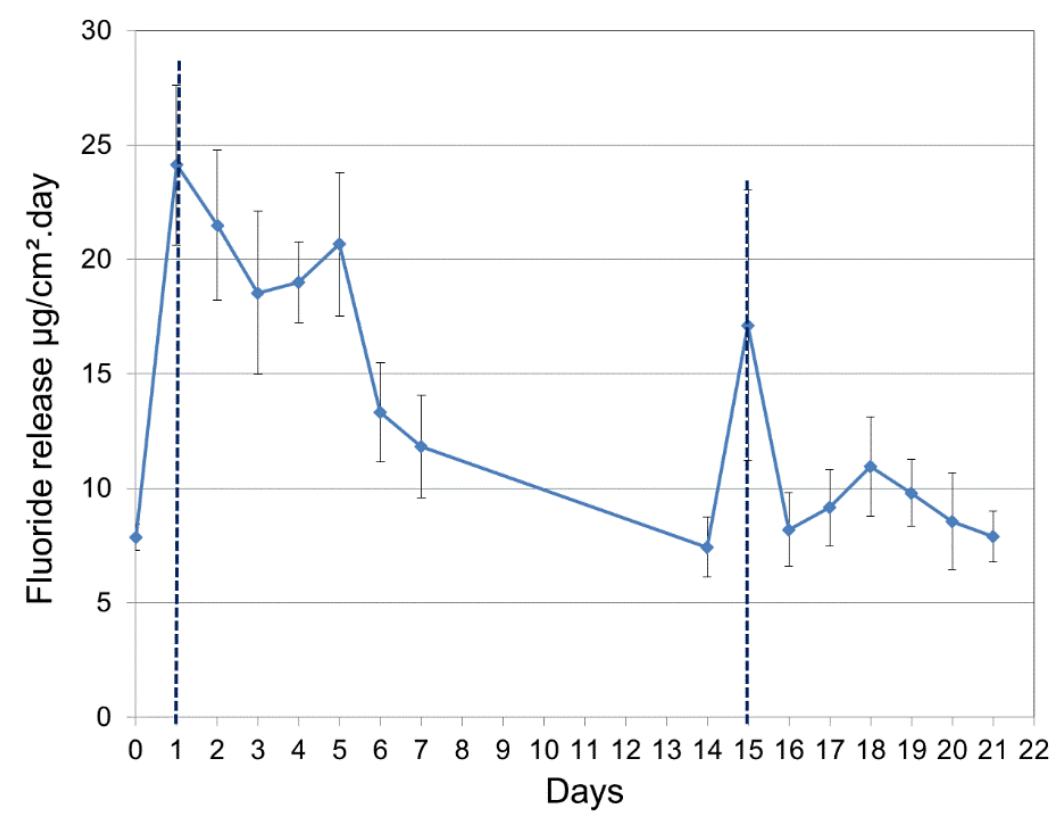


Figure 4
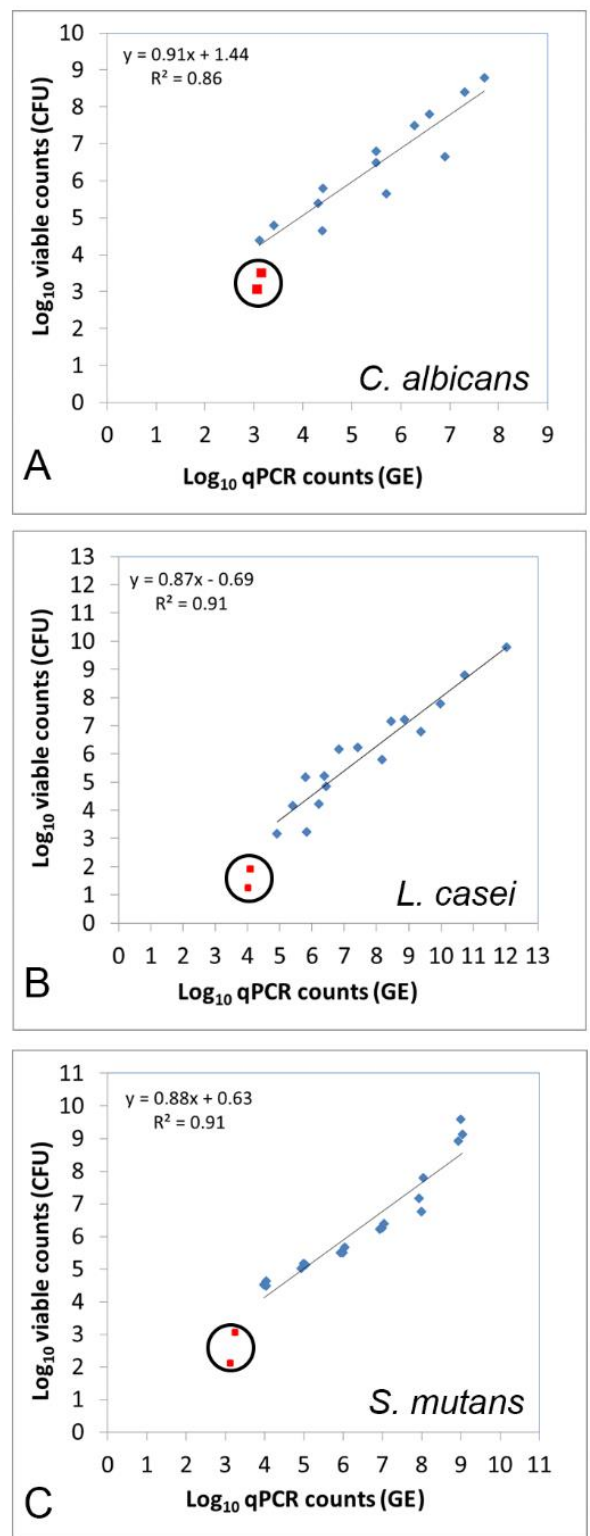
Figure 5

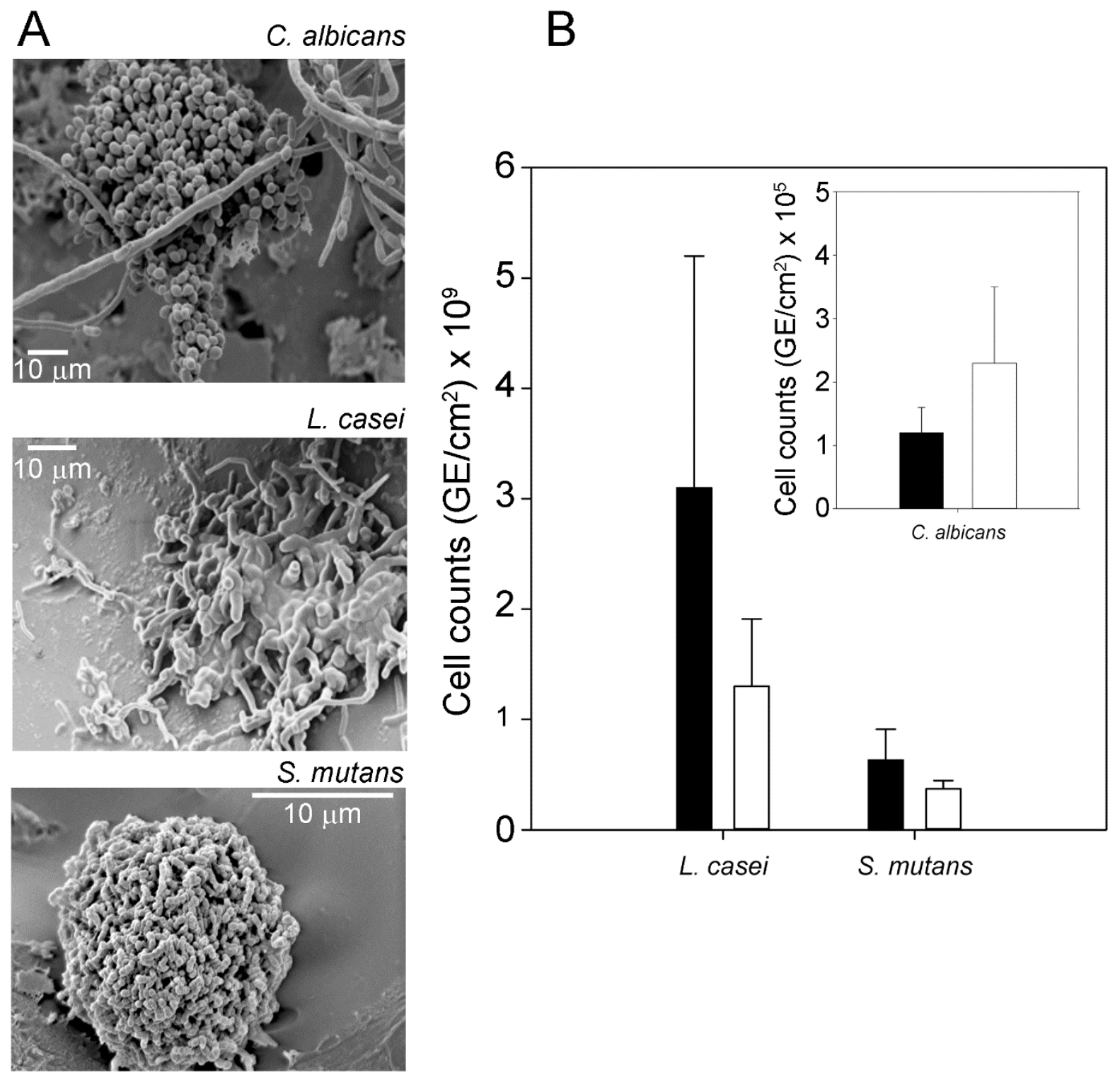


Figure 6
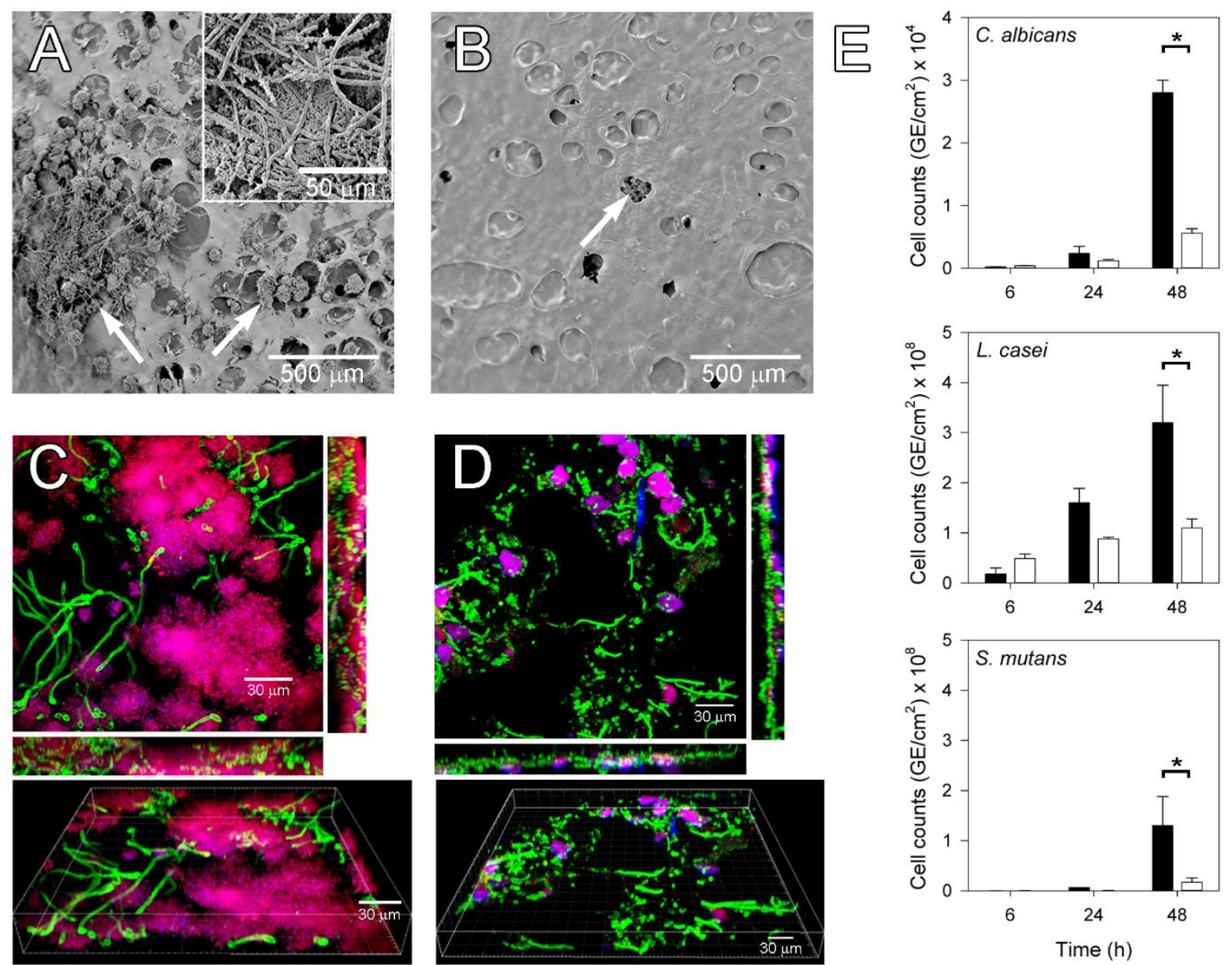